\title{
Theodoro Sampaio, Friedrich Ratzel e os Sertões de Euclides da Cunha
}

Theodoro Sampaio, Friedrich Ratzel, and Backlands: The Canudos Campaign of Euclides

\author{
da Cunha
}

Ricardo Alexandre Santos de Sousa

\section{Doutor em História das Ciências e da Saúde pela Casa de Oswaldo Cruz Professor Adjunto do Departamento de História - UESB ricsousa14@gmail.com}

\begin{abstract}
Resumo: $O$ presente trabalho trata da percepção dos sertões como possível espaço fundador da nacionalidade sob a ótica de dois intelectuais contemporâneos e que em suas interlocuções pensaram o caráter do sertanejo e a sua interação com o meio. A leitura dos sertões e dos sertanejos foi marcada naquela geração por um evento crítico, a Guerra de Canudos (1896-1897), que trouxe a figura do sertanejo e do sertão nordestino para o primeiro plano nas discussões acerca do caráter nacional. Em ambos os autores há subsumida a perspectiva de Friedrich Ratzel, em que o ser humano estaria intimamente ligado ao meio em que habita e disso deriva a sua possibilidade de progresso. Há, contudo nuances que diferenciam os intelectuais, Theodoro Sampaio mostrava-se menos fatalista do que o seu sucessor, Euclides da Cunha.
\end{abstract}

Palavras-chave: Sertões; Intelectuais brasileiros; Friedrich Ratzel.

\begin{abstract}
The present paper deals with the perception of the sertão as a possible founding space of nationality from the perspective of two contemporary intellectuals and who in their interlocutions thought about the character of the sertanejo and its interaction with the environment. The perception of the sertões and sertanejos was marked in that generation by a critical event, the Canudos War (1896-1897), which brought the figure of the sertanejo and the northeastern sertão to the forefront in discussions about national character. Both authors have subsumed the perspective of Friedrich Ratzel, in which the human being would be closely linked to the environment in which they live and their possibility of progress derives from that. There are, however, nuances that differentiate both intellectuals. Theodoro Sampaio was less fatalistic than his successor, Euclides da Cunha.
\end{abstract}

Keywords: Sertões; Brazilian intellectuals; Fridrich Ratzel. 
Definitivamente, o Brasil não foi descoberto. Ao chegarem à larga faixa de terras continentais posicionadas entre Portugal e as almejadas Índias com as suas ricas especiarias, os portugueses não descobriram o Brasil, mas começaram a inventá-lo. Inventar o Brasil foi, ou está sendo, um longo processo de constructos simbólicos.

Especialmente no século dezenove a construção do Brasil ganhava força com a independência e a necessidade de uma história nacional que não fosse um mero apêndice da história portuguesa. Justamente nesse contexto é que a possibilidade de uma leitura da nação a partir de seus sertões se faz viável. Seria aquele posto, sítio onde supostamente teria havido uma menor intervenção da metrópole na formação do caráter nacional. Dessa forma, os sertões pareciam o ambiente apropriado para dar ao Brasil feições de nação. Contudo, na luta pela hegemonia da interpretação histórica, isso não era um consenso e nem mesmo os que tomavam os sertões como gênese da nacionalidade os enxergavam da mesma maneira.

As trocas entre os saberes locais e as ciências oitocentistas tinham o papel fundamental de conferir à imagem da nação um caráter científico que viabilizasse a possibilidade de aceitação do projeto de civilização nos trópicos. Especialmente alguns letrados como Theodoro Sampaio (1855-1937), Capistrano de Abreu ${ }^{1}$ (1853-1927), Silvio Romero $^{2}$ (1851-1914) e outros participantes da geração de setenta do século XIX, procuravam através das ciências europeias uma interpretação do caráter nacional.

A proposta deste artigo é analisar a circulação de algumas das ideias que povoavam o universo daqueles que pensavam o Brasil como nação e as características que o tornava particular frente às outras nações estabelecidas. Nesse contexto, destacamos a figura de Theodoro Sampaio e Euclides da Cunha (1866-1909), bem como a troca de informações entre esses autores e a utilização de alguns conceitos do meio físico como formador da nação, conceito que foi sistematizado nas duas últimas décadas do século XIX pela antropogeografia de Friedrich Ratzel (1844-1904).

\footnotetext{
${ }^{1}$ Capistrano de Abreu ( 1853-1927) foi um dos mais renomados historiadores brasileiros das últimas décadas do século dezenove e início do século vinte. Era membro do Instituto Histórico e Gegográfico Brasileiro, IHGB e seus trabalhos históricos e etnográficos tornaram-se referência pelo apuro do método histórico.

${ }^{2}$ Silvio Romero (1851“1914) foi professor de filosofia do Colégio Imperial D. PedroII, preocupado com o caráter do brasileiro, diferenciando-o do português, advogava que o Brasil passava por um processo de branqueamento em que o elemento indígena já teria sido suplantado e que o processo de mestiçagem acabaria por fazer desaparecer o negro, num processo evolutivo natural.
} 
Evidentemente, outros autores foram utilizados na construção do caráter nacional, como o francês Hippolyte Taine ${ }^{3}$ (1828-1893), o inglês Herbert Spencer ${ }^{4}$ (1820-1903), Auguste Comte ${ }^{5}$ (1798-1857) e o positivismo francês. Logo a antropogeografia de Friedrich Ratzel, não pode ser vista como vertente única ou mesmo principal para outorgar cientificidade ao discurso dos intelectuais brasileiros na busca de um ideal de nação. Até mesmo porque muitas vezes os conceitos chegavam por vias transversas, chegando aos letrados brasileiros, por exemplo, através autores franceses. Logo, a apropriação dos autores citados e de outros pela intelectualidade brasileira, concorre para a construção do sentido de nação nas raias do cientificismo oitocentista.

O contato entre Theodoro Sampaio e Euclides da Cunha, ambos engenheiros, se deu a partir de em 1892, segundo relatou o baiano em artigo publicado em 1919 em homenagem ao amigo que completava naquele ano dez anos de falecido. Na época em que travaram contato, ambos trabalhavam junto à Superintendência de Obras, ligada à Secretaria de Obras Públicas de São Paulo e a princípio, os dois se viam espaçadamente, pois Euclides da Cunha no seu trabalho de engenheiro fazia muitas viagens pelo oeste paulista.

Segundo Theodoro Sampaio, quando Euclides da Cunha aparecia, depois desses longos intervalos era para contar-lhe sua odisseia e maldizer o seu tédio, que já se prolongava por muito tempo. Embora tivessem posições políticas díspares, já que o mais jovem, em sua formação militar, abraçara o positivismo e o materialismo. Isso, contudo não era empecilho para que os dois letrados discutissem temas ligados à vida literária.

Theodoro Sampaio descrevia o amigo como um homem decepcionado com a República, que não correspondia à imagem de seus sonhos de juventude, Euclides da Cunha também não se mostrava empolgado por seu trabalho como engenheiro, mas "trazia um ar de tédio a trair-lhe uma repugnância invencível” (SAMPAIO, XXXX: 86),

\footnotetext{
${ }^{3}$ Formado pela École Normal Supérieure, Hippollyte Taine (1828-1893), com base em ideias positivistas e cientificistas comuns à sua época, construiu uma vasta obra, cujo trabalho mais conhecido são os cinco volumes de Histoire de La Littérature Anglaise de 1864.

${ }^{4}$ Herbert Spencer (1820-1903) foi um dos filósofos ingleses amplamente divulgados em seu tempo. A abrangência de seus escritos pode se dar ao fato de basear suas ideias em leis universais de um tipo de evolucionismo que caminhava do homogêneo para o heterogêneo, aplicando tais princípio desde a formação do Universo até a sociedade, a economia e as raças humanas. Acabando por desembocar no chamado "Darwinismo Social".

${ }^{5}$ Auguste Comte (1798-1857) foi o filósofo idealizador do Positivismo francês. Segundo o seu Cours de Philosophie Positive, publicado em 1830, a humanidade passaria por três estágios em seu processo evolutivo. Os quais seriam o estado teológico, o estado metafísico e o estado positivo. Suas ideias foram amplamente divulgadas entre letrados brasileiros na segunda metade do século dezenove.
} 
parece que somente os escritos de combate conseguiam arrancar-lhe do tédio e despertar-lhe alguma paixão que o arrebatasse.

Um desses arrebatamentos se deu quando Euclides da Cunha começou a ler as notícias sobre a Guerra de Canudos. Conforme o engenheiro baiano o amigo voltou de uma se suas missões pelo interior animado, "era outro e tinha como que o pressentimento de que seu destino ia mudar" (SAMPAIO, xxx: 87). Foi em conversa na casa de Theodoro que Euclides da Cunha, impressionado com o fracasso da terceira expedição militar a Canudos, manifestou seu interesse pelo movimento do beato Antônio Conselheiro, que mobilizava as forças nacionais para a sua contenção e que, no entanto, fracassava vez após vez diante o exército de desvalidos que seguia a Antônio Conselheiro pelos áridos sertões.

Theodoro, mais velho, erudito e profundo conhecedor das plagas sertanejas foi quem forneceu a Euclides da Cunha os seus mapas do sertão baiano que lhe permitiu escrever um artigo com um amplo estudo geográfico e climático da região do vale Vaza-Barris, bem como uma análise dos aspectos étnicos e culturais do homem sertanejo. Além dos mapas, Theodoro orientou o jovem engenheiro e ajudou na redação do artigo, tirando dúvidas em questões geológicas e geográficas (VENTURA, 2003: 148 apud SANTOS, 2010: 165).

Em carta escrita ao amigo João Lúcio de Azevedo, historiador português, Capistrano de Abreu, membro do IHGB e um dos mais renomados historiadores do Brasil dizia: "sobre Euclides, muito influiu T. Sampaio, conforme este me disse, que não é gabarola" (ABREU, 1977: 80 - correspondência datada como "Boas saídas, melhores entradas de 1918 - noves fora 1").

São várias as referências que atestam a importância de Theodoro Sampaio na empreitada do Jovem amigo em viajar para o local do conflito de Canudos com o intuito de reportar como jornalista os acontecimentos. Tais referências vêm de diferentes autores, além das dos próprios Euclides da Cunha e Theodoro Sampaio. Em uma curta biografia sobre Theodoro Sampaio, Fábio Guimarães afirma" "Refiro-me à sua influência sobre Euclides da Cunha, particularmente na elaboração de Os Sertões" (GUIMARÃES, 1978: 40).

Embora não encontremos em "Os Sertões” referências diretas a Ratzel, o meio físico como chave de entendimento da população e gênese da raça é uma constante. Contudo, como já dito, muito da antropogeografia proposta por Ratzel chegava aos brasileiros por vias transversas. Poucos intelectuais, como Capistrano de Abreu, tinham 
acesso à língua alemã e aos escritos do germânico, ficando os outros à mercê de explicadores de língua inglesa ou francesa.

Parte da má fama de Ratzel se deve às duras críticas a ele dirigidas pelo historiador Lucien Febvre (1878-1956), quando este associou o alemão ao famigerado determinismo geográfico em contraposto a Vidal de La Blache (1845-1918), que seria associado por Febvre ao "possibilismo". Tal crítica acabou por gerar uma análise rasa e condenatória da obra de Ratzel, baseada no preconceito, já que o veredicto de Febvre é acatado por intelectuais que jamais leram sequer uma linha do autor alemão.

Para Febvre as concepções de Ratzel eram especialmente arbitrárias, pois, segundo ele, Ratzel procurava modelar uma vasta sociedade humana a partir das condições naturais que a análise geográfica revelava ao invés de pensar o homem a partir de seu trabalho (FEBVRE, 1970: 258). Evidentemente, não é prudente desconsiderar as críticas de Febvre à obra de Ratzel, contudo tomar a crítica pela obra é incorrer em grave erro.

Não pretendemos, entretanto, nesse artigo aprofundarmo-nos no modelo ratzeliano, mas, tomar apenas a sua ideia básica de que o meio pode impulsionar ou retardar o progresso humano. Evidentemente, ao tratarmos de progresso referimo-nos à perspectiva de cidadãos do século dezenove, como eram todos os intelectuais aqui visitados. Embora Ratzel criticasse de forma bastante aberta a visão eurocêntrica de seus contemporâneos, porém, no que se refere ao progresso, dificilmente o autor conseguiria escapar ao modelo europeu como o ideal (RATZEL, 1896: 4).

Outro ponto importante no modelo de Ratzel é o seu total descrédito na hierarquia das raças humanas. Para o alemão, em todo e qualquer lugar em que a Terra for habitável pelo homem, será encontrado membros da mesma e única raça humana. “[...] só há uma espécie de homem, variações são numerosas, mas não profundas. $\mathrm{O}$ homem, no sentido mais amplo é um cidadão da Terra" (RATZEL, 1896: 9) ${ }^{6}$.

No aspecto citado, vários outros autores oitocentistas seguiam o sentido diametralmente, relegando o germânico a uma voz dissonante dentre os letrados de fins do século XIX e início do século XX. Esses últimos tomavam o escalonamento racial como parte fundamental de suas análises sociais.

\footnotetext{
${ }^{6}$ As citações diretas da obra The History of Mankind de Ratzel nesse artigo são traduções livres, elaboradas por nós a partir da versão em inglês de 1896.
} 


\section{Sertões, um espaço imaginário}

No caso brasileiro, segundo Nísia Trindade Lima (1998), a desagregação do regime escravocrata e a transição para uma sociedade de classes teve papel fundamental na reflexão sobre aquela sociedade, no que se refere à identidade nacional e à integração dos diversos grupos sociais num projeto de civilização. Nas três últimas décadas do século dezenove e as três primeiras décadas do século vinte, questões como raça e herança colonial assumem crescente importância nas controvérsias da nascente intelligentsia (LIMA, 1998: 27).

Diante da escravidão ou da libertação dos cativos em todo o longo processo que ocorreu desde a proibição do tráfico (1831), passando pelas leis do Ventre Livre (1871) e dos Sexagenários (1885) e, por fim, a Lei Áurea em 1888, o Brasil viveu um processo eivado por contradições. Conforme a análise de Leo Spitzer (2001) percebe-se que o processo emancipatório se dá de forma coletiva, ou seja, toda uma classe escrava é posta em liberdade ou, uma parcela dela no que se refere às leis que antecederam à abolição. Entretanto, aos homens e às mulheres libertos não foi destinado qualquer projeto que viabilizasse a transição econômica e social para que a "liberdade" fosse de fato alcançada.

Sem projetos para que a população liberta pudesse conseguir um meio de vida alternativo e nem tampouco um projeto pedagógico para informá-los e reorientá-los, cultural e socialmente, a abolição acabou por servir à proletarização e à marginalização da população liberta que, competia no mercado de trabalho com imigrantes pobres e muitas vezes mais qualificados para a modernização do trabalho.

Em outras palavras, o processo de libertação se deu de modo coletivo e contraditoriamente o processo de inclusão obedeceu à lógica individualista e liberal do Laissez-faire (SPITZER, 2001: 34-35).

Como, evidentemente, a população liberta formada por pretos e mestiços não teve possibilidade de ascensão social e foi em grande parte empurrada para as margens da sociedade, teorias raciais e/ou climáticas, espaciais advindas do Velho Mundo e que davam margem à interpretação de "dois Brasis" ou "duas potencialidades de país" tiveram muita aceitação entre a elite letrada. Tais potencialidades que vão tomando a 
forma de regiões marcadas por antagonismos, ao menos na leitura da intelectualidade, que tinha sua gênese na elite local ${ }^{7}$.

Parece, que tal elite ao construir a sua própria identidade e, na ânsia de ser o mais possivelmente parecida com os povos, ditos civilizados, procurava um contraponto. Criando assim, fronteiras entre um Brasil civilizado ou civilizável e um Brasil bárbaro. Sendo o litoral uma fronteira imaginária com a Europa, logo o Brasil civilizado e o interior, o Brasil bárbaro.

A fronteira criada entre os dois Brasis confere à leitura da nação duas realidades distintas, em que o Brasil indígena, selvagem, mestiço e bárbaro, contrastava com o litoral, o Brasil europeizado. Cabia a este segundo, por meio de incursões pedagógicas ao interior, levar a civilização a toda a nação. Era esse o pensamento de intelectuais como Silvio Romero, Alberto Torres (1865-1917) e Oliveira Viana (1883-1951). Evidentemente, essa marcha civilizacional implicava em embranquecer as populações de forma a tornar viável o processo civilizatório.

Silvio Romero, por exemplo, defendia que o papel primordial na civilização brasileira cabia ao português; o indígena, tomado por ele como "raça geológica", desapareceria segundo a lei de Spencer que propunha que uma raça inferior ao entrar em contato com uma raça superior, tendia a aniquilar-se; já, o africano teria tido mais vigor, ao mesclar-se com o europeu. No entanto, sua cor seria apagada com o tempo e assim a raça superior prevaleceria ao final. ${ }^{8}$

A visão da nação bipartida entre litoral e sertão perpassou o imaginário da intelectualidade brasileira, embora os membros dessa intelectualidade tenham seguido por múltiplos caminhos, por vezes exaltando a força e a capacidade de resistência do sertanejo, por vezes condenando-o como raça despreparada para o progresso.

O sentido de fronteira entre um Brasil civilizado e um Brasil selvagem tem um caráter diferenciado daquele que se deu nos Estados Unidos. Enquanto nesse último, o movimento de fronteira tem o sentido de expansão da cultura puritana, colonizadora para o Oeste, interiorizando a dominação, conforme os trabalhos clássicos de Frederick Jackson Turner, no Brasil, fronteira, assumiu o sentido de simbiose de paisagens,

\footnotetext{
${ }^{7}$ Giberto Freyre percebeu a formação da elite intelectual brasileira a partir da vinda da Família Real Portuguesa para o Brasil, o que abriu um contrafluxo das elites locais que enviavam seus filhos para estudar direito ou medicina em Coimbra, Lisboa e outros sítios europeus (Ver: FREYRE, Gilberto. Sobrados e mucambos. Rio de Janeiro: Ed. Record, 1996).

${ }^{8}$ Ver ROMERO, Silvio. História da Literatura brasileira (Tomo 1. Brasília: Ed.UFS, 2001. e ROMERO, Silvio. Apud. ABREU, J. Capistrano de. O caráter nacional e as origens do povo brasileiro. O Globo: 21-1-1976. In: ABREU, J. Capistrano de. E.E. - 4ª. Série. pp. 6
} 
pessoas e culturas. (LIMA, 1998: 43). Consoante tal análise, o mestiço sertanejo adquiriu um caráter "fronteiriço", vivendo o encontro de diferentes culturas em seus hábitos, etnias e linguagens.

Contudo, o conceito de sertão guarda ambiguidades. A própria palavra, embora não exista consenso quanto à sua etimologia, seria oriunda de "desertão" o que em dicionários dos séculos XVIII e XIX tem o sentido tanto de lugar espacialmente isolado quanto de região pouco povoada (LIMA, 1998: 57).

Poucos foram os autores que perceberam a presença do indígena como agente histórico e, conforme Kaori Kodama (2009) ao indígena ficou relegado um "não lugar" no processo de formação do caráter nacional. A oposição entre tupis e tapuias, conferia aos primeiros uma imagem de indígena extinto ou assimilado que figurava no romantismo como na figura de Iracema e ao segundo a imagem de selvagem, decaído e em processo de desaparecimento ${ }^{9}$.

Assim, a opção do indígena como símbolo da nacionalidade, embora tivesse ampla aceitação na literatura romântica, não atentava para a tribos que viviam nos sertões como habitantes legítimos daquelas terras, mas encarava-os, muitas vezes, como obstáculos à penetração da "civilização" para o interior do continente.

Poucos autores, como Capistrano de Abreu e Oliveira Viana eram vozes dissonantes quanto ao mito do sertão enquanto espaço vazio. Capistrano, por exemplo, procurava através do trabalho que lhe consumiu grande parte dos anos, as gramáticas das línguas Caxinauá e Bacaerí, produzir documentos que permitissem aos historiadores avaliarem a participação indígena na formação do caráter nacional. Além disso, Capistrano de Abreu percebeu a introdução do gado como elemento fundamental para a ocupação dos sertões semiáridos, o que propiciou, diferentemente das incursões dos bandeirantes paulistas em busca de índios para escravizar e de minérios preciosos, núcleos de povoamento ${ }^{10}$.

A historiografia recente descreve um intenso fluxo comercial nas rotas sertanejas. A historiadora Isnara Ivo (2012) destaca, por exemplo, que em 1717 havia uma grande variedade de estradas e veredas que, não somente ligavam as capitanias do Rio de Janeiro, São Paulo e Minas, mas também uma vasta malha de caminhos entre

\footnotetext{
${ }^{9}$ Ver KODAMA, Kaori. Os índios no Império do Brasil - a etnografia do IHGB entre as décadas de 1840 e 1860. Rio de Janeiro: Ed. Fiocruz. São Paulo: EDUSP. 2009.

${ }^{10}$ Ver SOUSA, Ricardo. Capistrano de Abreu: História Pátria, Cientificismo e Cultura a Construção da História e do Historiador. Tese de doutorado, apresentada ao Curso de Pós-Graduação em História das Ciências e da Saúde da Casa de Oswaldo Cruz - FIOCRUZ, Rio de Janeiro, 2012.
} 
Minas e Bahia, em geral aproveitando as margens do São Francisco e seus afluentes. Tais caminhos e "descaminhos" facilitavam o contrabando do ouro e levava a Coroa a perdas consideráveis dos impostos a elas devidos pelos que exploravam o minério na colônia. Tais sertões eram "chamados de Babilônia confusa por Pedro Leonildo Maris e de a joia mais preciosa do Brasil pelo rei João V (1706-1750)" (IVO, 2012: 137).

Os relatos nos dão margem a inferir que o espaço sertanejo, embora identificado como vazio, não somente era parte integrante e vascularizada do corpo da nação desde a sua gênese, como permitiu formar núcleos de povoamentos com populações bastante mestiçadas.

A ambiguidade dos sertões também diz respeito ao seu território. Se em fins do século XIX e primeiras décadas do século XX o sertão vai cada vez mais ser identificado com o semiárido nordestino, entretanto, o conceito era bastante mais amplo. Sendo qualificado como sertões todos os espaços que iam para além da estreita faixa de terra da ocupação litorânea. O médico e romancista Afrânio Peixoto, professor de Higiene da Faculdade de Medicina do Rio de Janeiro, afirmava na Primeira República que o sertão, no Brasil, começava no ponto onde terminava a Avenida Central (LIMA, 1998: 60).

Investigar, portanto, as potencialidades sertanejas era buscar o próprio sentido da Nação. A fundação do IHGB em 1838 concorreu para isso. Consoante Manuel Salgado Guimarães em um artigo intitulado "Nação e Civilização nos Trópicos" (1988), no ano de 1840, o cônego Januário da Cunha Barbosa lançou um desafio no, então, recémcriado Instituto Histórico Geográfico Brasileiro. Definia-se um prêmio para o trabalho que melhor elaborasse um plano para se escrever a história do Brasil. O vencedor foi, ironicamente, o bávaro Philipp von Martius com o texto "Como se deve escrever a História do Brasil" publicado na revista do IHGB em 1845 e premiado no ano de $1847^{11}$.

Pensar a Nação, demandava pensar os seus sertões e pensá-los sob a ótica da ciência oitocentista, de forma que as reflexões acerca do caráter do brasileiro tivessem o respaldo da ciência do Velho Mundo. Autores como Theodoro Sampaio e Euclides da Cunha precisavam do aval científico para que suas obras alcançassem reconhecimento não somente no Brasil, mas no exterior.

${ }^{11}$ GUIMARÃES, Manoel L. S. (1988). Nação e civilização nos trópicos: o Instituto Histórico e Geográfico Brasileiro e o projeto de uma história nacional. Estudos Históricos. Rio de Janeiro, no. 1/5. pp.12-13. 
A visão dicotômica entre litoral e sertão, em que ao segundo atribui-se a percepção de o "outro Brasill", visto como isolado, abandonado, doente, nômade, atrasado, resistente à mudança ou despossuído, mostra-se bastante persistente na elite intelectual e pretendemos analisá-la sob o ponto de vista de dois importantes homens de letras de fins do século dezenove e início do século vinte.

\section{Theodoro Sampaio}

Theodoro Sampaio (1855-1937) era um homem negro, filho da escrava Domingas da Paixão, de ascendência gegê e do padre Manoel Fernandez Sampaio.

Aos nove anos de idade Theodoro foi retirado do convívio da mãe e dos irmãos e mudou-se com o pai para São Paulo e, posteriormente, para o Rio de Janeiro para dar continuidade a seus estudos.

Apesar das dificuldades que enfrentava, Theodoro teve ótimo desempenho nos estudos. Dificuldades por ser um jovem negro em meio a uma elite social que se queria branca. Tal elite, ainda que mestiça tal como o jovem Theodoro, tinha a vantagem de não exibir na cor da pele a ascendência escrava de forma evidente como ele, o que era um facilitador nas relações sociais e profissionais que constavam no horizonte de expectativas de um jovem estudante de engenharia no império.

A despeito de sua formação profissional o baiano circulou por várias áreas do saber, sendo invariavelmente bem recebido nos diversos campos.

Theodoro foi autor de obras como, "O Rio São Francisco e a Chapada Diamantina" (1906), fruto de suas observações como engenheiro participante da Comissão Hidráulica que percorreu o rio São Francisco a partir de sua foz, sob a direção do engenheiro americano Wiliam Milnor Roberts; "O Tupi na geografia nacional" (1901); "Atlas dos Estados Unidos do Brasil" (1908); "Dicionário histórico, geográfico e etnográfico do Brasil" (1922); "História da Fundação da Cidade de Salvador", obra póstuma publicada em 1949 durante o I Congresso de História da Bahia.

Além dos supracitados trabalhos, todos disponíveis, há uma infinidade de artigos sobre os mais variados temas, alguns compilados e reunidos em livro como "São Paulo no século XIX e outros ciclos históricos" publicado em 1978 e outros artigos, ensaios, 
cartas e diários que se encontram depositados no Instituto Geográfico e Histórico da Bahia, que presidiu em 1922; Biblioteca Nacional no Rio de Janeiro e Instituto Histórico e Geográfico de São Paulo, do qual foi membro fundador em 1894.

Sua formação se deu no momento em que as fronteiras entre os diversos conhecimentos eram bem mais plásticas do que as que conhecemos. Isso possibilitou ao engenheiro de formação um tipo de saber que nos é vedado na atualidade, posto que as especializações colocaram barreiras muito mais demarcadas entre as diversas áreas do conhecimento.

Não há, contudo, nos escritos de Theodoro qualquer fatalismo. Na Repartição de Águas e Esgotos de São Paulo entre 1902 e 1904, foi um dos diversos trabalhos que executou na área de saneamento ao longo de sua vida. Vislumbrou o crescimento futuro da cidade e a captação de água já insuficiente para aquele momento. Assim, o engenheiro propunha uma intervenção radical que aproveitava os mananciais mais elevados como o da Serra da Cantareira e não desprezava as águas do rio Tietê. Defendia que fossem mantidas intactas as áreas verdes no entorno dos mananciais dos rios e córregos para preservar o abastecimento para as gerações futuras (BERNARDINI, 100 2012: 206-207).

O exemplo supracitado é um dos que nos permite afirmar que toda a trajetória de Theodoro Sampaio foi pautada pelo princípio de que o homem se insere na natureza e que a intervenção daquele sobre essa deve levar em conta o bem-estar das populações em geral, a preservação do meio e o melhoramento das condições de vida.

Em suma, observamos em Theodoro Sampaio o mérito de pensar as populações locais inseridas na paisagem que as cercava. $\mathrm{Ou}$, no dizer dos nossos dias, no meio ambiente. A partir da segunda metade do século vinte, historiadores, geógrafos, antropólogos esquivaram-se de pensar a natureza como variante importante na história das populações e na construção da identidade local, por temerem a alcunha de deterministas. Contudo, cada vez mais o meio natural tem entrado como variável na análise de tais pesquisadores, especialmente quando a humanidade se dá conta da implicação das mudanças climáticas nos rumos tomados pela humanidade. $\mathrm{O}$ aquecimento global, por exemplo, que há algum tempo nos parecia um evento distante, tem atingindo seriamente as populações, seja com o nível de elevação de oceanos que têm submergidos zonas litorâneas e até mesmo ilhas inteiras, seja com mudanças climáticas radicais que incidem diretamente na produção agrícola, provocando períodos de escassez de alimentos. 
Ao pensar o homem como inserido no meio ambiente e, por conseguinte o meio como variável importante no processo de desenvolvimento, Theodoro, aproximava-se em certa medida da antropogeografia de Friedrich Ratzel.

A obra fundamental de Ratzel, Antropogeographie, foi publicada em 1882 e nela o autor procurava por meios de bases científicas - citando Montesquieu, Alexander von Humboldt (1769-1859), Henry Thomas Buckle (1821-1862), Carl Ritter (1779-1859), Oscar Ferdinand Peschel (1826-1875) e outros - construir um conceito de análise da humanidade a partir do meio em que se encontrava cada diferente grupo.

Segundo David Knight (1981), Humboldt foi responsável por renovar a forma de classificar espécies de plantas no século dezenove. Ao invés de recolher uma amostra sem qualquer referência mais precisa de seu habitat, Humboldt procurava destacar a paisagem local em que tal espécie se inseria, o que denominava de "províncias geológicas" $" 12$.

Ratzel, entretanto, não somente adaptava a perspectiva Humboldtiana de paisagem para a antropogeografia, pensando o ser humano inserido em seu meio de origem, como introduzia no conceito a perspectiva evolucionista darwiniana, a qual Humboldt não teve acesso, já que faleceu em 1859, ano em que Darwin publicou, “A Origem das Espécies".

Dessa forma, o alemão tomava o meio, não de forma fatalista, como muitos de seus leitores o fizeram, mas pensava que o ser humano como único, capaz e criativo independente das chamadas "raças". O meio era para ele um cenário que poderia favorecer ou dificultar o desenvolvimento.

Na citada expedição pelo rio São Francisco, Theodoro Sampaio reuniu vários exemplos de regiões em que o desenvolvimento se dava mais facilmente do que em outras. Para tal Theodoro fez uma detalhada descrição da população, que estava sempre acompanha a descrição da paisagem como se fosse dela uma extensão. O autor elencou assim, três níveis de associação do homem com o ambiente. No primeiro, um meio que oferece poucas possibilidades para o desenvolvimento da agricultura e de trabalho produtivo, abrigando uma população empobrecida e pouco desenvolvida no padrão de civilização tomado como modelo, herdado da perspectiva eurocêntrica do século dezenove; no segundo nível há a percepção de degradação da população que outrora viveu algum ciclo de desenvolvimento, mas que por algum motivo tal ciclo não teve

\footnotetext{
${ }^{12}$ KNIGHT, David (1981). Ordering the world - a history of classifying man. Londres: Brunet Books, pp. $116-117$.
} 
continuidade, entrando assim num processo de degradação e, por fim, algumas poucas localidades onde a paisagem local oferecia condições favoráveis à produção de riquezas com as quais a população conseguia alcançar algum nível de desenvolvimento, segundo o padrão civilizatório europeu, já que como um homem de seu tempo, Theodoro tem tal padrão como modelar.

Em seu texto, há paragens descritas como a seguinte: "O trecho do rio, que acabávamos de percorrer, para cima de Pão de Açúcar, é, de fato, um estreito canhão de margens escarpadas e pedregosas, onde o gnaisse e o micaxisto predominam e dão à paisagem esse tom áspero e enegrecido, das regiões estéreis e quase despidas de vegetação" (SAMPAIO, 2002: 71-72).

O autor continua notando naquele trecho que a população é escassa e as culturas quase desaparecem. As povoações que se avizinhavam daquela área viviam com o pouco que podiam produzir e os homens expelidos do alto sertão pela seca procuravam trabalho na linha férrea que se construía pelo governo imperial. Mulheres e crianças, para não padecerem dependiam de assistência pública e de parte do salário dos maridos que trabalhavam na construção da linha férrea.

Em contrapartida, há paragens como a região de Caetité, onde quedou-se por quatro dias, durante a festa de Reis, colhendo relatos com a população e informações sobre a região.

O clima justifica a produção. Aqui, como nas regiões vizinhas sobre a Chapada, colhem-se quase todas as frutas da Europa. Ensaiou-se o trigo com vantagem na fazenda Cajueiro, do Major Francisco Pereira de Castro, e conseguiu-se colher grão na razão de 480 litros por um de semente. Visitando pela manhã o mercado da cidade, que parecia uma feira bastante frequentada, notei, além dos requeijões, couros e outros produtos da indústria pecuária, abundância de legumes, batatas-inglesas, batatas-doces, inhames, hortaliças, abóboras, melões excelentes, grandes e boas melancias , mendubis, muito milho, arroz, feijão, rapadura, açúcar, excelente farinha de mandioca que, segundo me informaram, é aqui a produção mais avultada, principalmente na freguesia de Umburanas, nos distritos dos Furados e de Caculé, no rio do Antônio, exportando-se dela em tão larga escala para outros municípios que com certeza se considera Caetité o celeiro próvido destes sertões (SAMPAIO, 2002: 213). 
Não há, entretanto, da parte de Theodoro, qualquer fatalismo. Tanto na solução para o abastecimento de água em São Paulo, como nas regiões mais castigadas pela seca, o autor advoga que o poder público deve agir para prover a população de instrumentos para que se dê o desenvolvimento.

Theodoro Sampaio e Euclides da Cunha foram colegas engenheiros e mantiveram interlocução muito frutífera. Como já citado, a gênese de Os Sertões teria se dado nas conversas dos dois engenheiros.

\section{Euclides da Cunha}

Nascido no município de Cantagalo, no Rio de Janeiro em 1866, cursou a Escola Politécnica e a Escola Militar da Praia Vermelha. No ano de 1902, a obra mais conhecida de Euclides já havia sido publicada com grande repercussão: Os Sertões.

Como já mencionado, foi a partir de suas conversas com Theodoro Sampaio, que Euclides da Cunha muniu-se do material necessário para a empreitada no sertão baiano, onde se desenrolava a batalha entre as tropas governistas e os revoltosos ligados ao beato Antônio Conselheiro. A obra, resultante da missão jornalística do engenheiro Euclides da Cunha deve ser analisada de forma bidimensional, já que claramente pretende transitar o campo científico e literário.

A característica bidimensional da obra estava bastante em acordo com a proposta naturalista, bastante difundida em fins do século dezenove, a partir dos escritos de Émile Zola na França e que em fins do século XIX teve alguns expoentes no Brasil como Machado de Assis com Memórias Póstumas de Brás Cubas (1880); Aluísio de Azevedo, autor de obras como O Mulato (1881) e O Cortiço (1890); Adolfo Caminha, autor de O Bom Crioulo (1895); Júlio Ribeiro, autor de A Carne (1888), dentre outros.

O Realismo procurava desvincular-se do idealismo das narrativas românticas, atendo-se assim a uma maior realidade na descrição dos costumes em geral, nas relações entre sexos em particular e também num senso menos convencional no estilo e na análise dos caracteres. Inserido na literatura realista estava o Naturalismo, o qual predominou em muitos escritores a partir dos anos 1860 e 1870 e caracterizava-se por ser um tipo de realismo que procurava "explicar cientificamente a conduta e o modo de 
ser das personagens por meio de fatores externos, de natureza biológica e sociológica que condicionam a vida humana" (CÂNDIDO, 2008: 285-286).

O movimento naturalista não se ateve somente à literatura, mas a rejeição ao idealismo romântico e a busca de explicações científicas para a realidade acabou por influir outros literatos como se pode ver na história com Joaquim Nabuco (1849-1910), Capistrano de Abreu (1853-1927), Oliveira Lima (1867-1928); estudiosos da língua como Pacheco Júnior (1842-1899), Júlio Ribeiro (1845-1890), Araripe Júnior (18421899), José Veríssimo (1857-1916); ensaístas e pensadores como Tobias Barreto (18391889), Clóvis Beviláqua (1859-1944), Eduardo Prado (1860-1901), Farias Brito (18641917) e Euclides da Cunha (1866-1909) (CÂNDIDO, 2008: 282).

Portanto, uma boa leitura de Os Sertões tem como norte a percepção de que seu autor procurava se inserir no debate científico de sua época buscando argumentação para as suas hipóteses na ciência oitocentista e também não se pode deixar de perceber suas intenções literárias na profusão de metáforas e na própria métrica do texto que, muitas vezes assume a estética poética.

Para Raymond Williams (1979) as perspectivas de sentimentos/pensamentos não se opõem, mas se complementam construindo a consciência prática de uma determinada época. Em Os Sertões a integralidade da obra será apreendida nessas duas dimensões. De um lado a expressividade no campo científico, como é o caso da geologia e da geografia que costuram o texto e, por outro lado, na condição humana do autor, que como narrador agencia efeitos estéticos de forma a passar ao leitor o sentimento que um brasileiro do litoral tem ao deparar-se com os sertões longínquos de seu país com suas paisagens e suas gentes (LAGARES \& MEDEIROS, 2018: 134).

Euclides, como já dito, não faz no livro qualquer menção direta a Ratzel, porém nota-se como hipótese muito clara a percepção de que o homem somente pode ser bem compreendido se inserido no meio em que habita e mais do que isso, que tem em Humboldt uma referência, tal processo é analisado à luz do evolucionismo. Ou seja, o sertanejo e as misturas de raça que o engendraram fazem parte de um processo plástico de formação daquela população específica a qual difere da população litorânea com a qual é frequentemente comparada. Contudo, diferentemente de autores como Capistrano de Abreu, Euclides mostra-se fatalista. Tal população estaria fadada ao desaparecimento.

A estrutura do livro já demonstra o quanto o cenário é importante na obra de Euclides da Cunha. O autor fora enviado ao local do conflito como correspondente 
especial de $O$ Estado de São Paulo para escrever o dia-a-dia da Guerra de Canudos. No entanto ao invés de tão somente relatar o conflito, Euclides divide a obra em três blocos: A Terra, O Homem e A Luta, o que mostra que para o autor a luta não se dá de forma fortuita, mas é decorrência de algo maior, um choque de fronteiras ou antes de culturas produzidas em espaços diversos.

Passemos à análise de alguns trechos da obra:

É uma paragem impressionadora.

As condições estruturais da terra lá se vincularam à violência máxima dos agentes exteriores para o desenho de relevos estupendos. O regímen torrencial dos climas excessivos, sobrevindo, de súbito, depois das insolações demoradas, e embatendo naqueles pendores, expôs há muito, arrebatando-lhes para longe todos os elementos degradados, as séries mais antigas daqueles últimos rebentos das montanhas: todas as variedades cristalinas, e os quartzitos ásperos, e as filades e calcários, revezando-se ou entrelaçando-se, repontando duramente a cada passo, mal cobertos por uma flora tolhiça - dispondo-se em cenários em que ressalta predominante, o aspecto atormentado das paisagens (CUNHA, 2003: 40-41).

Ao discorrer sobre a terra, o clima, a vegetação, Euclides da Cunha procurou descrever minuciosamente todo o caminho por ele percorrido até chegar ao lugar onde se deu o conflito final entre o grupo de Antônio Conselheiro e as tropas governamentais. $\mathrm{Na}$ sua descrição não faltam os tipos de solos e formações rochosas, bem como os regimes de chuva e os pequenos povoamentos pelos quais passou. É interessante notar como o autor atribui ao terreno características que posteriormente vai encontrar nos sertanejos, filhos daquelas paragens, como se um fosse o prolongamento do outro de uma forma muito direta o que denota uma leitura um tanto equivocada das propostas antropogeográficas de Ratzel, mas que não deixa de ter uma referência à derivação da civilização ao meio em que se encontra socialmente estabelecida.

Outra característica interessante e que reforça a posição do autor é atribuir ao meio físico qualidades humanas como o excesso, a violência, o tormento e, na continuidade do texto, tais característica sintetizam-se na mudança abrupta do clima seja no calor do dia para a queda vertiginosa da temperatura noturna seja na mudança da estação de extrema secura para a estação de chuvas torrenciais que varrem do solo degradando-o à dinâmica portentosa das tormentas (CUNHA, 2003: 41). 
$\mathrm{Na}$ sequência do relato, o primeiro ser humano detalhadamente descrito é um soldado morto. A descrição é profundamente poética e funciona como um primeiro indício da violência do embate entre as duas civilizações.

O sol poente desatava, longa, a sua sombra pelo chão, e protegido por ela braços largamente abertos, face volvida para os céus, - um soldado descansava.

Descansava... havia três meses.

[...] E estava intacto. Murchara apenas. Mumificara conservando os traços fisionômicos, de modo a incutir a ilusão exata de um lutador cansado, retemperando-se em tranquilo sono, à sombra daquela árvore benfazeja. Nem um verme - o mais vulgar dos trágicos analistas da matéria — lhe maculara os tecidos. Volvia ao turbilhão da vida sem decomposição repugnante, numa exaustão imperceptível. Era um aparelho revelando de modo absoluto, mas sugestivo, a secura extrema dos ares (CUNHA, 2003: $56-57)$.

A poética descrição do soldado morto parece mostrar como o terreno seco do semiárido tem a potencialidade de tornar parte de si próprio os seres que sobre ele pousam por algum tempo. O corpo do soldado morto, mumificado pela secura do ar parece em perfeita harmonia como o espaço físico. Chega a parecer que o cadáver tem algum gozo em quedar-se de braços abertos sob a quixabeira alta que sobranceia a vegetação franzina (CUNHA, 2003: 57).

A narrativa de Euclides da Cunha marcada por figuras literárias e postulados científicos procura dar continuidade entre o meio físico e o sertanejo. Tal narrativa, plena de contrastes abruptos e contradições mostra que no caráter do sertanejo, o autor percebe as mesmas características e mudanças abruptas. Degradação e grandiosidade, brutalidade e poesia, indolência e heroísmo são contrastes presentes tanto no espaço quanto no homem.

Uma figura elencada por Lagares e Medeiros (2018) deixa bem claro esse contraste. Quando Euclides vale-se de dois personagens para descrever o sertanejo, os quais seriam Hércules-Quasímodo. A descrição do sertanejo como desgracioso, desengonçado, torto, que exibe a fealdade típica dos fracos, o andar sem firmeza, sem aprumos, ao manifestar displicência e ao descansar bamboleante agachado e apoiado apenas sobre os dedões do pé e sentado sobre os calcanhares. Tal figura parece ao 
escritor detentora de uma simplicidade ao mesmo tempo ridícula e adorável (CUNHA, 2003: 157).

Para Euclides, o sertanejo é "antes de tudo um forte" (CUNHA, 2003: 157). Esse Hércules/ Quasímodo é um contraste parecido com os antagonismos que percebe no clima, no terreno e no regime de chuvas. Seguindo o Texto Euclides atesta a transformação do Quasímodo em Hércules,

Nada é mais surpreendedor do que vê-la desaparecer de improviso. Naquela organização combalida operam-se, em segundos, transmutações completas. Basta o aparecimento de qualquer incidente exigindo-lhe o desencadear das energias adormecidas. O homem transfigura-se. Empertiga-se, estadeando novos relevos, novas linhas na estatura e no gesto; e a cabeça firma-se-lhe, alta, sobre os ombros possantes aclarada pelo olhar desassombrado e forte; e corrigem-se-lhe, prestes, numa descarga nervosa instantânea, todos os efeitos do relaxamento habitual dos órgãos; e da figura vulgar do tabaréu canhestro reponta, inesperadamente, o aspecto dominador de um titã acobreado e potente, num desdobramento surpreendente de força e agilidade extraordinárias (CUNHA, 2003: 158).

$\mathrm{Na}$ sequência, Euclides atesta que apesar de cavaleiro chucro e deselegante o vaqueiro conduz-se com destreza por meio aos espinhos mordentes, protegido por sua armadura de couro, montado nos pequenos cavalos, sem arreios e aí, nada pode contêlos, acervos de pedras, coivaras, moitas de espinhos ou barranca de ribeirões.

De um extremo ao outro em um curto lampejo de tempo tal como a seca que se converte em chuva torrencial, o sertanejo se transmuta de figura lânguida e deplorável a herói elástico e veloz em meio ao espinhal.

Ao descrever o combate, quando as tropas do governo avançam na caatinga em perseguição aos revoltosos, a luta se faz desigual, já que a vegetação do sertão mostrase parcial na batalha,

A força, de baionetas caladas, rompe, impetuosa, o matagal numa expansão irradiante de cargas. Avança com rapidez. Os adversários parecem recuar apenas. Nesse momento surge o antagonismo formidável da caatinga.

As seções precipitam-se para os pontos onde estalam os estampidos e estacam ante uma barreira flexível, mas impenetrável, de juremas. Enredam- 
se no cipoal que as agrilhoa, que lhes arrebata das mãos as armas, e não vingam transpô-lo. Contornam-no. Volvem aos lados. Vê-se um como rastilho de queimada: uma linha de baionetas enfiando pelos gravetos secos. Lampeja por momentos entre os raios do sol joeirados pelas árvores sem folhas; e parte-se, faiscando, adiante, dispersa, batendo contra espessos renques de xiquexiques, unidos como quadrados cheios, de falanges, intransponíveis, fervilhando espinhos [...] (CUNHA, 2003: 309).

Assim, os soldados, perdidos num labirinto de galhos caem presos por fortíssimos tentáculos e debatem-se desesperadamente em meio aos espinhos que lhes rasga o uniforme, enquanto o sertanejo velozmente atravessa o cipoal e se esconde.

A figura utilizada por Euclides para mostrar a inabilidade das tropas em meio à caatinga e a destreza do sertanejo no seu próprio meio é representada por outra figura bem interessante. A sucuri flexuosa com o touro pujante (CUNHA, 2003: 540).

O touro, espécie exógena, trazido aos sertões pelas mãos do colonizador parte para o ataque de forma direta, com sua força descomunal, sua imponência e seus chifres agudos que causam temor a todos os seres. No entanto, a sucuri conhece o seu espaço e o seu corpo. Ela não desperdiça esforços em vão. Vence a luta justamente por fazer com que o seu opositor gaste as suas forças no ataque direto, no excesso de confiança que deposita em sua força e na contundência de seus cornos.

$\mathrm{Na}$ busca de validação científica para as suas proposições poéticas, Euclides da Cunha abraça teses variadas e as vezes contraditórias. Se em algum momento parece conceber a raça tão somente como uma variação do meio físico, em outros parece pensar, diferentemente de Ratzel, que as raças têm entre si qualidades essenciais, ainda que as tome como derivação de um processo de adaptação ao meio físico. Ainda assim, não foge à hierarquização eurocêntrica dos grupos raciais, em que o indo-europeu seria o elemento gerador da civilidade. Por outro lado, a mestiçagem, quanto mais variada, traria consequências maléficas aos indivíduos.

É que nessa concorrência admirável dos povos, evolvendo todos em luta sem tréguas, na qual a seleção capitaliza atributos que a hereditariedade conserva, o mestiço é um intruso. Não lutou; não é uma integração de esforços; é alguma coisa de dispersivo e dissolvente; surge, de repente, sem caracteres próprios, oscilando entre influxos opostos de legados discordes. A tendência 
à regressão às raças matrizes caracteriza a sua instabilidade (CUNHA, 2003: 152).

Em decorrência de uma tendência instintiva à busca de uma situação de equilíbrio "o mulato teria um desprezo irresistível pelo negro" e procuraria o intercurso com indivíduos que "apagassem de sua prole o estigma da fronte escurecida”, “já o mamaluco faz-se bandeirante, precipitando-se ferozmente contra as cabildas aterradas [...]" (CUNHA, 2003: 152).

Nos sertões, devido ao isolamento o intercurso entre os três tipos fundamentais, o negro, o índio e o branco teria se dado de forma bem menos reduzida que no litoral. Ali, na visão de Euclides, o negro não teria tido grande penetração. Assim, a índole incoerente e revoltada do mestiço de diversas matizes presentes no litoral, não teria se difundido naquelas terras, produzindo assim uma sub-raça com características muito homogeneizadas tanto no físico quanto no temperamento. Além disso, tal raça estava em contato com um meio bastante selvagem, que não lhe demandava como no litoral de um grau de complexidade civilizatória para o qual ainda não se encontrava preparada. Assim, uma raça primitiva encontrava-se plenamente adaptada ao meio em que se encontrava e, não fosse o contato com brasileiro litorâneo tenderia a desenvolver-se lentamente, segundo as leis do evolucionismo (CUNHA, 2003: 153-156).

Percebe-se que Euclides da Cunha via no sertanejo, inserido em seu ambiente valores mais admiráveis do que nos mestiços do litoral. Parece evidente no texto um latente preconceito contra o negro e o mestiço de origem africana, tudo evidentemente coberto por um verniz científico.

Assim, o sertanejo era um forte por se encontrar plenamente inserido no meio em que se estabelecera e por isso era tão difícil às tropas governamentais sobrepujarem o exército de desvalidos que seguia o beato Antônio Conselheiro em seu próprio ambiente.

O sertanejo era a sucuri lutando em seu habitat natural contra o touro imponente deslocado de sua terra natal.

\section{Considerações finais}

A circularidade de ideias em fins do século dezenove e início do século vinte faz com que a intelectualidade brasileira, ávida por uma explicação cientifica de aceitação 
internacional para o caráter do brasileiro, buscasse em autores do Velho Mundo a legitimação de suas ideias sobre a proposta de uma nação civilizada nos Trópicos.

O processo de independência fez com que tal empreitada se tornasse até mesmo um projeto governamental, já que o imperador D. Pedro II estava muito atento à ciência do Velho Mundo. Contudo, as teorias raciais mais contundentes, como as proposições de Joseph Arthur de Gobineau (1816-1882), Louis Agassiz (1807-1873) ou Cesare Lombroso (1835-1909), relegavam pouco ou nenhum espaço no mundo civilizado para países como o Brasil, que saídos do processo colonizador encontravam-se profundamente mestiçados.

Outra possibilidade era pensar o brasileiro a partir do meio físico. Embora tal proposta nem sempre fosse alvissareira para os Trópicos, pois desde, o conde de Buffon (1707-1788), o barão de Montesquieu (1689-1755) e outros pensadores europeus o clima tropical era visto como capaz de degenerar a vida.

A intelectualidade brasileira, numa ação quase instintiva tendeu a filiar-se a várias vertentes científicas sem, contudo, abraçar fielmente uma ou outra. Longe de isso ser visto como um tipo de fraqueza intelectual, acreditamos que havia uma releitura das ideias do Velho Mundo, de forma a tornar o discurso do intelectual brasileiro aceito do outro lado do Atlântico, bem como pensar estratégias civilizatórias para o Brasil.

Ratzel e a antropogeografia por ele proposta, tinha o mérito de pensar o processo civilizacional como uma derivação do intercâmbio entre o homem, o meio e as trocas com outros grupos humanos. Tal equação dava uma margem maior de variáveis que alguns brasileiros, com maior ou menor aprofundamento nas premissas do autor alemão procuravam manipular em sua leitura do Brasil.

Theodoro Sampaio tinha em seus estudos os atributos geográficos e climáticos como fundamental para pensar as populações nos diferentes sertões dos Brasil. Contudo, Theodoro não se mostrava um fatalista. Procurava demandar do Estado, por meio de políticas públicas condições para que a fagulha do desenvolvimento fosse acessa nos diversos lugares em que trabalhou. Tal como em Ratzel, Theodoro percebia alguns fatores facilitadores do desenvolvimento e outros que o podiam atrasar.

Na citada Comissão Científica pelo Rio São Francisco, chefiada pelo engenheiro estadunidense Willian Milnor Roberts entre 1879 e 1880, o engenheiro baiano descreveu as várias localidades e a população ribeirinha, atentando para as possibilidades que o terreno proporcionava e o grau de desenvolvimento da região. Contudo, seu olhar esteve atento para formas de suprir as carências de cada região, de 
forma a promover algum desenvolvimento, como no já mencionado porto de Piranhas, “onde o gnaisse e o micaxisto predominam e dão à paisagem esse tom áspero e enegrecido, das regiões estéreis e quase despidas de vegetação" (SAMPAIO, 2002: 72).

Naquelas paragens, o governo distribuía socorros para a população faminta e que, segundo Theodoro tais víveres poupavam da desgraça uma grande parcela da população (SAMPAIO, 2002: 73). Já em Caetité, o engenheiro teve outra impressão. Trata-se de um lugar de fartura e em suas palavras, "o clima justifica a produção". Lugar onde se colhia frutas, fazia-se requeijões, produtos de couros e outros derivados da pecuária (SAMPAIO, 2002: 213).

Havia em Theodoro o desejo de promover a civilização, ainda que fosse evidente que o modelo civilizacional era o europeu. Já Euclides da Cunha, mostra-se um tanto fatalista. Embora reconheça no brasileiro dos sertões a gênese da brasilidade de forma mais original do que a que percebia no litoral e, embora visse o sertanejo quase como uma continuidade do solo e do clima em que se encontrava, parece pensar como os darwinistas sociais de seu tempo, que a população em estágio de evolução menos avançada como seriam as dos sertões, ao entrarem em contato com uma raça mais avançada, tenderiam a desaparecer. Embora, ponderasse que havia no sertanejo uma subcategoria étnica já formada, liberta por condições históricas de uma civilização de empréstimo.

Tivesse aquela população o tempo necessário para desenvolver-se, o processo evolutivo trataria de produzir um tipo brasileiro totalmente adaptado e com as qualidades devidas ao seu meio. Contudo, tal civilização estaria fadada a desaparecer. Assim, os sertões como gênero dramático seria uma tragédia.

Parece notório que as visões de mundo e experiências pessoais dos autores tendem, ainda que inconscientemente, a ter participação na opção histórica e na maneira como eles/nós fazemos uso dos instrumentos mentais que acionamos para interpretar a vida. Logo, a leitura de Ratzel ou mesmo o contato indireto com os princípios defendidos pelo alemão para o desenvolvimento civilizacional passa por uma série de filtros interpretativos quando aplicados ao vivido, como no caso de Theodoro Sampaio e Euclides da Cunha. 


\section{Referências bibliográficas}

ABREU, Capistrano de (1977). Obras de Capistrano de Abreu - Correspondência v.2. Ed. Organizada por José Honório Rodrigues. Rio de Janeiro: Ed. Civilização brasileira.

(1976). Ensaios e estudos: critica e história, 4 $4^{a}$ série. Rio de Janeiro: Civ.Brasileira.

BERNARDINI, Sidney Piochi (2012). Três propostas para a solução do abastecimento de água em São Paulo (1902-1904). Revista do Programa de Pós-Graduação em Arquitetura e Urbanismo da FAUUSP, São Paulo, v. 19, n. 32, p. 198-218.

CÂNDIDO, Antonio José A. C. (2008). Presença da Literatura Brasileira-das origens ao Realismo, História e Antologia. Rio de Janeiro: Bertrand Brasil.

CUNHA, Euclides da (2003). Os Sertões. São Paulo: Ediouro.

FEBVRE, Lucien (1970). La Terre et l'evolution humaine - Itroduction Géographique à l'histoire. Paris: Èditions Albin.

FREYRE, Gilberto (1996). Sobrados e mucambos. Rio de Janeiro: Ed. Record.

KNIGHT, David (1981). Ordering the world - a history of classifying man. Londres: Brunet Books.

GUIMARÃES, Manoel L. S. (1988). Nação e civilização nos trópicos: o Instituto Histórico e Geográfico Brasileiro e o projeto de uma história nacional. Estudos Históricos, Rio de Janeiro, no. 1/5.

KODAMA, Kaori (2009). Os índios no império do Brasil - a etnografia do IHGB entre as décadas de 1840 e 1860. Rio de Janeiro: Ed. Fiocruz. São Paulo: EDUSP.

LAGARES R., Fernanda \& MEDEIROS A. (2018). Euclides. Narrativa e Cientificismo: A construção literária dos sujeitos de Canudos em Euclides da Cunha. Territórios e Fronteiras, vol.11 (1), p. 132-152.

LIMA, N. Trindade (1999). Um sertão chamado Brasil. Rio de Janeiro: Ed. Revan: IUPERJ: UCAM.

RATZEL, Friedrich (1986). The history of mankind (vol.I). Londres, Nova Iorque: Macmillan and Co. Ltda.

ROMERO, Silvio (2001). História da Literatura brasileira. Tomo 1. Brasília: Ed.UFS.

SAMPAIO, Theodoro (2002). O rio São Francisco e a Chapada Diamantina. São Paulo: Cia das Letras.

. (2000). Recordando Euclides da Cunha (no décimo aniversário de sua morte). In: CUNHA, Euclides da (1866-1909). Um paraíso perdido: reunião de ensaios amazônicos/ Euclides da Cunha; seleção e coordenação Hildon Rocha. Brasília: Senado Federal, p. 85-94.

SANTIAGO, João Phelipe (2013). Espaço Geográfico e Geografia do Estado em Friedrich Ratzel. Vitória da Conquista: Edições UESB.

SANTOS, Ademir Pereira (2010). Theodoro Sampaio nos sertões e nas cidades. Rio de Janeiro: Versal.

WANKLIYN, Harriet (1961). Friedrich Ratzel - A Biographical Memoir and Bbliography. Cambridge: Univercity Press.

Artigo recebido em 20 de outubro de 2019. 
Aprovado em 03 de junho de 2020.

DOI: $10.12957 /$ intellectus.2020.46048 